\title{
Retroanálise de escorregamento de talude na área de risco do Taquaril,
}

\section{Belo Horizonte, MG}

\author{
Maria Giovana Parizzi ${ }^{1}$, Frederico Garcia Sobreira ${ }^{2}$, Terezinha Cássia de Brito Galvão ${ }^{3}$, \\ Marcos Antônio Timbó Elmiro ${ }^{4}$, Elder Antônio Beirigo ${ }^{5}$
}

1- Departamento de Geologia - IGC/UFMG. Av. Antônio Carlos 6627, Instituto de Geociências, UFMG. CEP: 31270 - 901, mgparizzi@msn.com;

2- Departamento de Engenharia Ambiental - UFOP. R. Diogo de Vasconcelos, 122, CEP 35.400-000 Ouro Preto-MG, sobreira@degeo.ufop.br; 3- Spelman College, 350 Spelman Lane S.W. Atlanta, GA 30314-4399, tcgalvao@spelman.edu;

4- Departamento de Cartografia - IGC/UFMG. Av. Antônio Carlos 6627, Instituto de Geociências, UFMG. CEP: 31270 - 901, mtimbo@ufmg.br; 5- Vale S.A. Eng. Sênior - Rua Castro Alves, no 1225, Bairro São José. Divinópolis. CEP: 35501 -205, eabeirigo@yahoo.com.br

Recebido em 18 de setembro de 2011; aceito em 25 de outubro de 2011

RESUMO: A região do Taquaril em Belo Horizonte abriga mais de 30.000 habitantes adensados em uma pequena área de 145,2 ha. Durante períodos chuvosos, mais de $60 \%$ dessa área se enquadra nas categorias de alto risco de escorregamento. Um talude representativo da maioria dos taludes presentes na área foi escolhido para a execução de um estudo de retroanálise de sua estabilidade. Foi observado que, as ações antrópicas, associadas às características geológicas desfavoráveis dos terrenos, são as principais causas dos escorregamentos. 0 terreno caracteriza-se por encostas bem inclinadas, constituídas por filitos e xistos alterados, cobertos por depósitos de tálus e colúvio inconsolidados. Os depósitos de tálus e colúvio retardam a saturação das descontinuidades dos maciços rochosos e o fator de segurança de rupturas planares e em cunha, nestes casos, é superior a um. A retroanálise apontou baixa resistência para os depósitos de encosta. Pequenas taxas de precipitação podem desencadear escorregamentos de menor volume, mas, durante chuvas intensas, as superfícies de ruptura se tornam mais extensas e profundas, geralmente atingindo o contato entre solo e maciço.

Palavras-chave: Retroanálise, escorregamentos, Taquaril.

ABSTRACT: SLOPE STABILITY BACK ANALYSIS: A CASE STUDY AT TAQUARIL SLUM, BELO HORIZONTE CITY, BRAZIL. Taquaril risk area is located close to Belo Horizonte city, Brazil. Over $60 \%$ of this area was evaluated as being prone to landslides. A representative $25 \mathrm{~m}$ slope in this area was chosen to perform a retro-analysis of their stability. It has been observed that antropic actions associated with geological and geomorphological characteristics of the area are the main causes of landslides. Steepy inclined slopes composed by weathered phyllites and schists and also by unconsolidated colluvium and talus deposits characterize the terrain. Topography is being modified and heaps of garbage and waste material from constructions are daily thrown along the slopes and drainages, creating piles of waste deposits placed in unstable conditions. Nowadays shallow landslides are more numerous and dangerous than wedge and planar failures of rock mass, which presents low permeability despite the presence of fractures set. Saturation of the rock mass when covered by slope deposits is difficult to occur and, in this case, the safety factor for wedge or planar failure is up to one. Geotechnical analysis has shown low resistance values for slope deposits. Low precipitation rates may causes shallow slide surfaces, but during intense rain these surfaces are deeper, almost enclosing the rock mass contact.

Keywords: retro-analysis, landslides, Taquaril

\section{INTRODUÇÃO}

No Brasil, os escorregamentos destacam-se como o tipo de acidente de origem geológica mais comum, principalmente no período das chuvas. Muitos eventos dessa natureza têm ocorrido, causando acidentes em várias cidades, principalmente nas capitais onde a ocupação desordenada e acelerada avança cada vez mais para terrenos geologicamente desfavoráveis à ocupação.

Belo Horizonte, possuindo uma população que ultrapassa 2 milhões de habitantes, é um clássico exemplo dessa situação. Dados fornecidos pela Secretaria da Habitação e da Coordenadoria de Defesa Civil de BH revelam uma média anual de 400 ocorrências de escorregamentos entre os anos de 1994 a 2000 em vilas distribuídas em nove regiões do município. Em janeiro de 2003 as chuvas extrapolaram os volumes esperados de precipitação e inúmeros escorregamentos ocorreram. Como conseqüência, foram registradas nove mortes, incluindo 6 crianças soterradas, 67 feridos, muitas casas destruídas, além de 756 famílias desabrigadas. A partir daí a prefeitura municipal iniciou um amplo trabalho de redução dos riscos de escorregamentos que vêm refletindo bons resultados, observados pela redução de acidentes com vítimas fatais e inúmeras obras e remoções nas áreas de risco. Para contribuir com a redução de acidentes, um estudo sobre a estabilidade de taludes na Vila Taquaril foi realizado. A vila do Taquaril está entre as que possuem maior número de ocorrências de escorregamentos. Os escorregamentos neste local são desencadeados principalmente por fatores antrópicos, decorrentes da ocupação desordenada em terrenos com aspectos morfológicos e geológicos desfavoráveis. Atualmente, a região do Taquaril abriga mais de 30.000 habitantes adensados em uma pequena área de 145,2 ha. Parizzi et al. (2002) revelam que, em períodos chuvosos, mais de $60 \%$ dessa área se enquadra nas categorias de risco alto e iminente. Apesar da existência do cadastro dessas áreas, durante os períodos chuvosos a avaliação das condições de risco iminente e a recomendação da retirada dos moradores de suas casas ainda consistem em tarefas difíceis. Acredita-se que essa dificuldade se deva principalmente à falta de dados qualitativos e quantitativos sobre os mecanismos de 
ruptura mais comuns nas áreas de risco. A falta de um banco de dados consistente, que forneça parâmetros geológicos e geotécnicos capazes de subsidiar as ações interventoras do risco a escorregamentos é um grande problema.

Visando contribuir para a construção de um banco de dados que possa ser utilizado no aprimoramento dos métodos de elaboração de planos preventivos de defesa civil, este artigo apresenta um modelo do mecanismo de ruptura de um talude do Conjunto Taquaril, que é representativo da situação de risco do local. Foi realizada uma retroanálise da estabilidade do talude após a sua ruptura em Janeiro de 2003. Os resultados obtidos forneceram os parâmetros de resistência e de poro pressões prevalecentes no momento da ruptura.

\section{MÉTODOS}

Para a realização da retroanálise do escorregamento foram reconstituídas as condições geotécnicas e geométricas existentes no talude no momento da ruptura, de acordo com a metodologia de Fontoura et al. (1984), Duncan (1996), Augusto Filho \& Virgilli (1998), dentre outros. A análise do Talude Taquaril envolveu os seguintes procedimentos:

Escolha de um talude no conjunto do Taquaril que fosse representativo da situação de risco iminente. A análise de estabilidade do talude se iniciou antes de sua ruptura em janeiro de 2003, sendo possível aquisição de dados topográficos do talude e parâmetros do material do talude antes da ruptura.

Execução de nova topografia, na escala 1:150, para obtenção da geometria do talude após a ruptura.

Caracterização do maciço rochoso através de inspeções geológicas de campo, incluindo o mapeamento das camadas litológicas presentes no local e a medição das descontinuidades conforme os aspectos de rugosidade, abertura, persistência, preenchimento e condições de umidade. Estas medidas foram executadas de acordo com as instruções da ISRM (1983).

Os dados obtidos das inspeções geológicas de campo foram tratados através dos Sistemas de classificação dos maciços rochosos RMR de Bieniawisk (1989) e Sistema Q de Barton (1974). A análise de estabilidade do maciço foi executada seguindo-se os critérios da análise cinemática das descontinuidades, com o auxílio de projeção estereográfica, e da análise de equilíbrio Limite de acordo com Hoeck \& Bray (1981), com o auxílio dos programas "Planar Failure Analysis e Wedge Failure Analysis" desenvolvidos por Krueger (1999) e Krueger (2000).

Distinção entre os diferentes depósitos existentes ao longo da face do talude: tálus, colúvio e aterro.

Caracterização física dos depósitos encontrados, através de ensaios de laboratório e de campo. Amostras deformadas e indeformadas da matriz dos depósitos foram coletadas para a execução dos ensaios laboratoriais do tipo: granulometria, limites de liquidez e plasticidade, massa específica dos grãos e cisalhamento direto com amostras inundadas, massa específica natural.

Ensaios em campo da permeabilidade dos depósitos, executados com o auxílio do permeâmetro Guelph .

O programa XSlope (Balaam, 2001) foi utilizado para a execução da retroanálise da ruptura circular ocorrida em Janeiro de 2003. O programa se baseia no método simplificado de Bishop (1955) para rupturas circulares. Os valores de poro pressão foram simulados a partir do coeficiente de poro pressão $r_{u}$ estabelecido por Bishop \& Morgenstern (1960). Valores de resistência foram obtidos através de ensaios de cisalhamento direto com amostras inundadas.

Vistoria do talude durante o período chuvoso de novembro de 2002 a janeiro de 2003 para registrar possíveis escorregamentos e correlacioná-los às taxas diárias de precipitação do período.

\section{DESCRIÇÃO DA ÁREA DO CONJUNTO TAQUARIL}

\section{1 - Aspectos naturais}

O Conjunto Taquaril situa-se no extremo leste do Município de Belo Horizonte, em sua porção sul, na área limítrofe com o Município de Sabará (Fig.1). Está inserido na porção norte do Quadrilátero Ferrífero onde afloram rochas das Seqüências Metassedimentares (Silva et al. 1995), mais precisamente, filitos, xistos e metagrauvacas do Grupo Sabará em avançado estado de alteração. Além das unidades do Grupo Sabará, destacam-se aqui grupos de depósitos recentes, inclusive tecnogênicos, diferenciados por sua origem, granulometria e estado de consolidação. O entalhe do relevo tem sido vigoroso, devido à altitude representativa da área, entre 795 e 1040 m, à pré disponibilidade litológica e ao clima. Os vales são muito encaixados, em especial junto às cabeceiras, e se alargam próximo à jusante. 
O clima local caracteriza-se por uma estação seca bem pronunciada, com duração de 3-4 meses, de maio a agosto. Grande parte da média anual de precipitação de $1381 \mathrm{~mm}$ é concentrada entre outubro e Abril, quando Janeiro é o mês mais chuvoso.

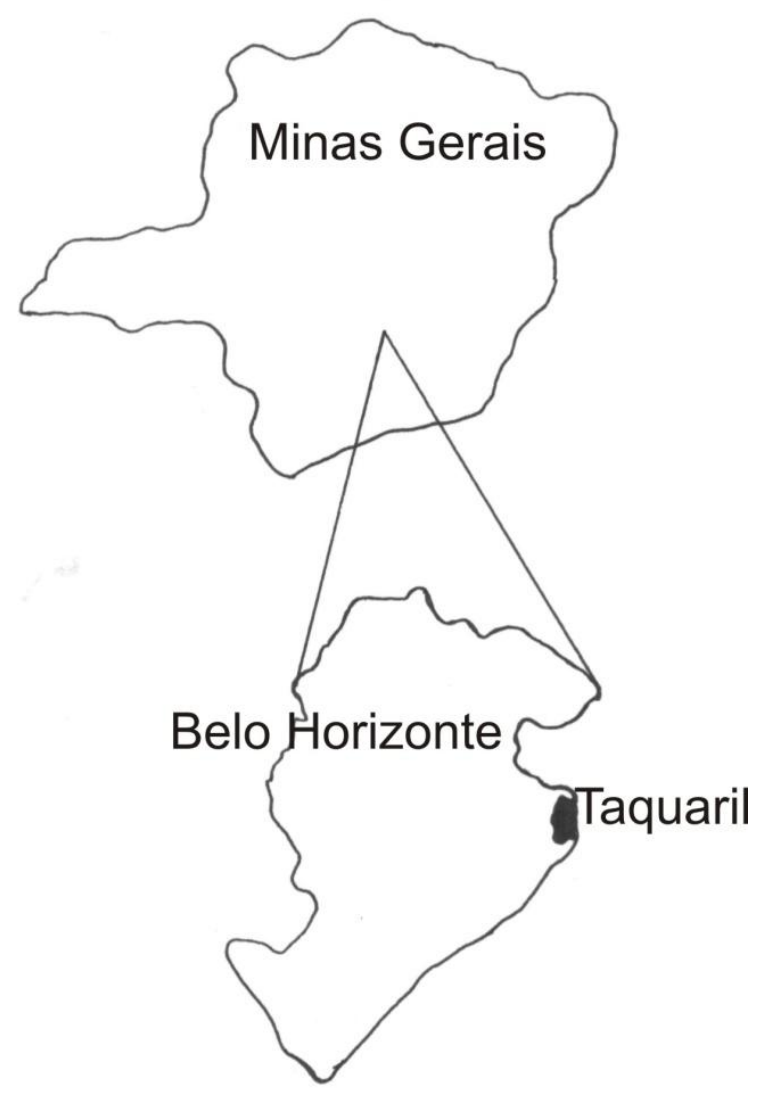

Figura 1 - Croqui de localização do Conjunto Taquaril

\section{2 - Formas de uso e ocupação}

Neste trabalho utilizam-se as definições de Augusto Filho (1995) que consideram taludes como áreas restritas que apresentam cortes antrópicos. 0 termo encosta será utilizado para designar superfícies mais amplas naturalmente inclinadas, podendo conter os taludes.

A paisagem original da região já foi fortemente modificada devido à intervenção antrópica. A erosão é intensa e o padrão de ocupação irregular, o que, somado às características geomorfológicas e litoestruturais das rochas do Grupo Sabará, torna o risco de escorregamento alto. A tipologia das edificações é muito precária, com casas de madeira, lona, telhas de zinco e até mesmo de papelão. Os fatores mais agravantes relacionados às edificações são a fundação - na maioria das vezes inexistente ou mal projetada - e o tipo de corte feito no talude. Os moradores fazem cortes verticalizados nas encostas íngremes para construírem seus barracos. Lançam a terra descartada e lixo encosta abaixo, criando depósitos inconsistentes sobre a rocha. Em seguida, outros moradores fazem cortes nesses depósitos e constroem seus barracos sem fundação diretamente sobre esses materiais.

Novamente lançam terra descartada e lixo encosta abaixo e, assim, rapidamente cria-se grande quantidade desses depósitos nas encostas do Taquaril. As casas são também muito próximas aos taludes de corte ou até apoiadas nestes, como ilustrado na Figura 2. Embora já conhecido como uma área de risco, o Conjunto Taquaril a cada ano tem apresentado acelerado aumento da população e do número de moradias. As Figuras 3 e 4 mostram registros de fotografias aéreas da área do Conjunto Taquaril nos anos de 1989 e 1994, exibindo a intensificação da ocupação ao longo desses cinco anos

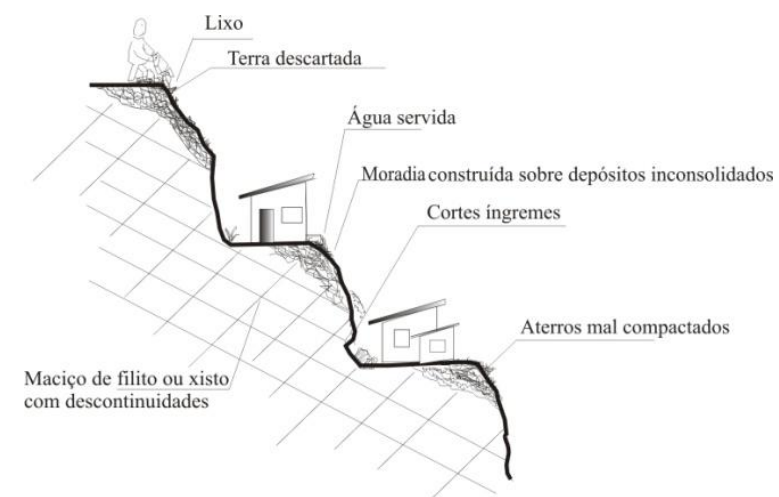

Figura 2 - llustração da forma de uso e ocupação das encostas do Taquaril

O talude escolhido para a análise da estabilidade é representativo da maioria dos taludes presentes no Conjunto Taquaril (Fig.4). Localiza-se em encosta voltada para noroeste e apresenta inclinação de $46^{\circ}$, suavizando para $36^{\circ}$ próximo ao topo e altura de $25 \mathrm{~m}$. Antes do escorregamento de Janeiro de 2003 já apresentava sinais de movimentação e cicatrizes de escorregamentos anteriores (Fig. 4), o que o caracterizava como um talude com risco iminente de ruptura. Alguns moradores já haviam deixado o local. Em janeiro de 2003 o talude sofreu novo escorregamento (Fig. 5) de maiores proporções. 

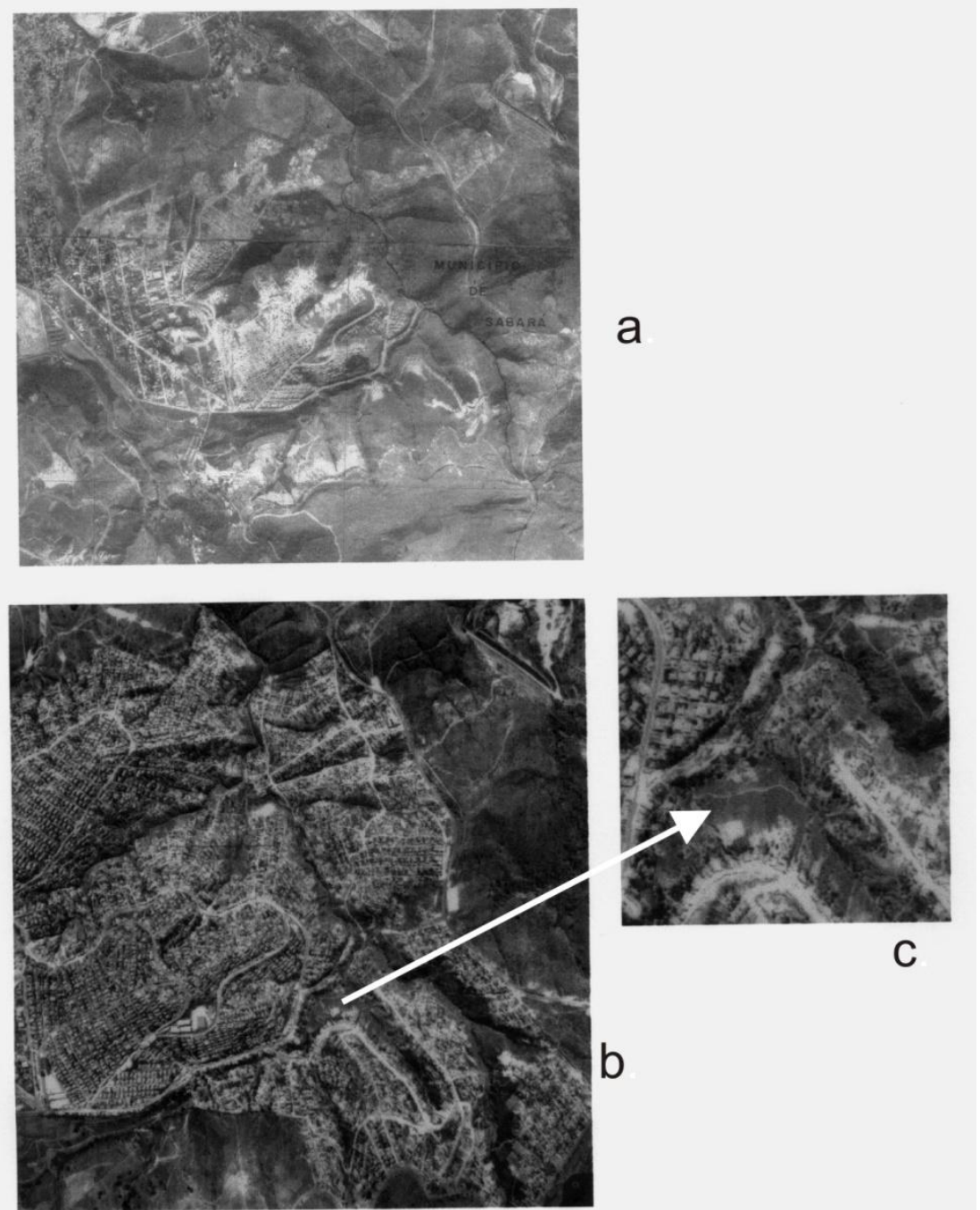

C

Figura 3 - a) Foto aérea (1:10.000) do Conjunto Taquaril em 1989, b) Foto aérea (1:8000) do Conjunto Taquaril em 1994 e C) Foto aérea ampliada (1:5000) do local do talude analisado, conforme indica a seta.

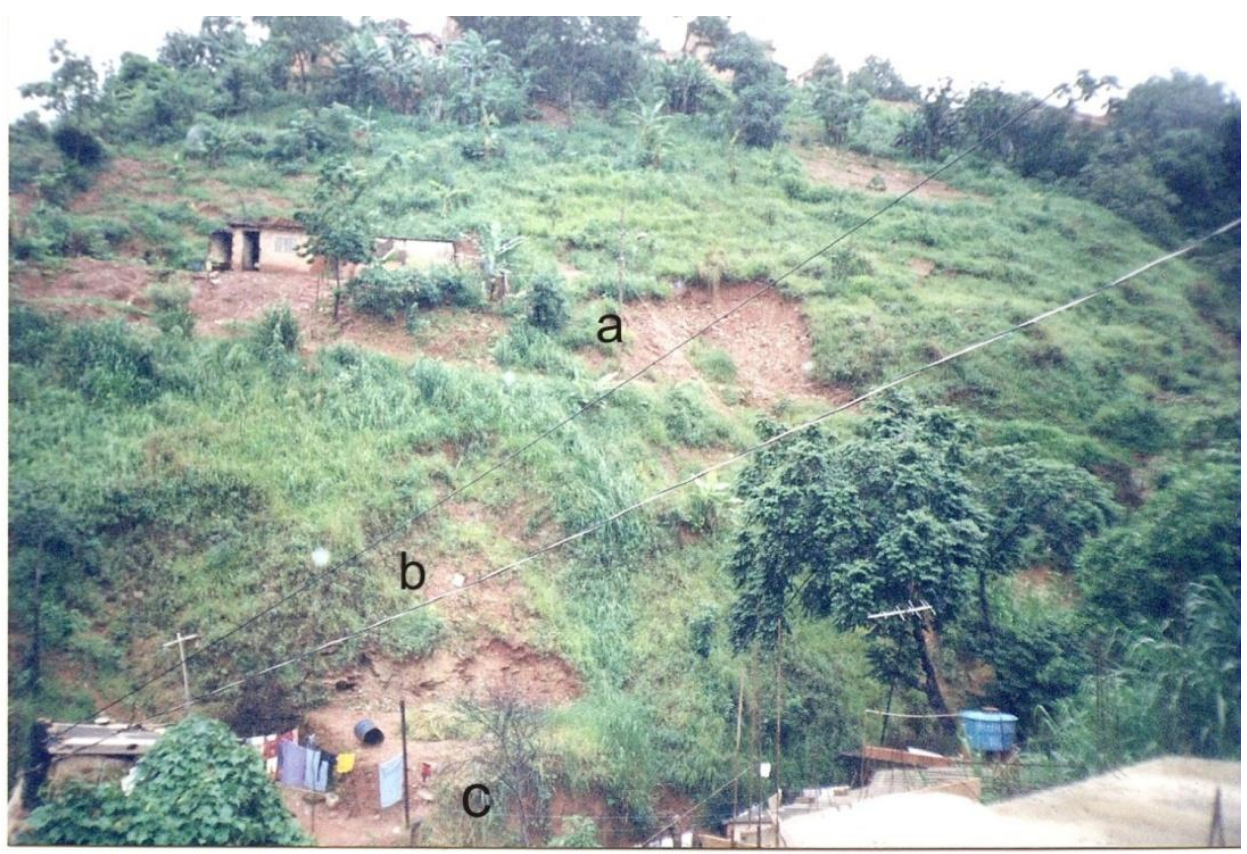

Figura 4 - Vista Geral do Talude analisado no Taquaril - Data da Foto: 06 de janeiro de 2003. a) depósito de tálus, b) colúvio e c) aterro 


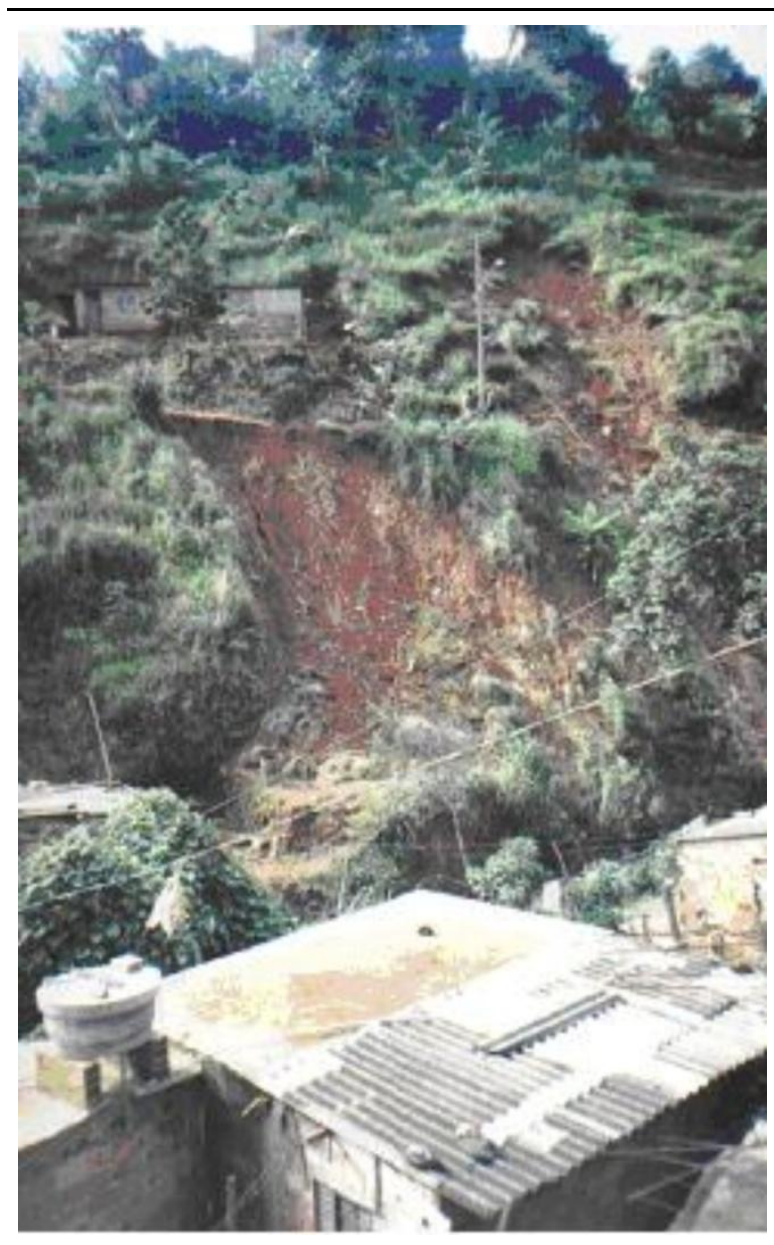

Figura 5 - Vista do Talude Taquaril após o escorregamento ocorrido em 15 de Janeiro de 2003.

\section{RESULTADOS}

\section{1 - Análise geológica e geotécnica}

No talude analisado o maciço é constituído por filito fino intercalado a grauvaca do Grupo Sabará. Devido a seu avançado estado de alteração, chega a ser classificado como saprolito. As rochas apresentam foliação penetrativa, preservando esta estrutura mesmo quando decomposta. Quando fresca, mostra-se muito resistente, porém, quando muito alterada e exposta, se desplaca tão facilmente que chega a apresentar comportamento pulverulento. As superfícies de descontinuidades são, muitas vezes, manchadas por óxidos.

De acordo com Piumbini et al.(1999) as porções filíticas extremamente finas, clorito-muscovíticas, alternam-se com porções com proporção significativa de quartzo, em torno de 30 a 40\%. A descrição microscópica da grauvaca indicou mineralogia constituída por clorita, muscovita, quartzo, plagioclásio, óxidos e em menor proporção de epidoto, turmalina e zircão.
O maciço é coberto por três tipos diferentes de material, dependendo da posição do talude: Depósitos de tálus originados do filito, colúvio avermelhado e aterro, como indicado na Figura 4. A distinção desses materiais foi baseada apenas em sua aparência macroscópica, ou seja, análise de campo e na análise granulométrica (Tabela 1).

Depósito de tálus: Material proveniente do Filito do Grupo Sabará. Localiza-se mais ao topo do talude, em contato com o filito alterado, apresentando nítidos sinais de movimentação como degraus de abatimento em superfície côncava. Constitui-se por matriz mais fina, silto arenosa, envolvendo pedregulhos de filito e grauvaca. A espessura do depósito é variável, em torno de $1,5 \mathrm{~m}$, e foram vistas constantes quedas desse material. Sua extensão ao longo da face do talude é grande cobrindo praticamente toda face superior do mesmo. Diferencia-se do colúvio por estar com coloração semelhante à rocha alterada e ser menos argiloso.

Colúvio avermelhado: Material localizado na face inferior do talude. Pelo aspecto macroscópico é um depósito mais antigo que os depósitos de tálus, possuindo coloração mais avermelhada e maior volume de matriz argilo-siltosa (Tabela 1) envolvendo pedregulhosos de filito e grauvaca. Também apresenta espessura de 1,5m.

Aterro: Chama-se aqui de aterro o material retrabalhado pelos moradores. Geralmente é compactado manualmente para a construção de barracos. O material de aterro é avermelhado e geralmente constituído por alguns fragmentos de xisto/filito e grauvaca em uma vasta gama granulométrica. Os fragmentos são geralmente planares, orientados de maneira caótica ou seguindo a declividade do terreno, em meio a uma matriz argilo-siltosa, podendo ter material orgânico associado e algum lixo. Por vezes estão cobertos por vegetação. Localizam-se em pequenas áreas, neste caso na base do talude, apresentando em média de 2 a $3 \mathrm{~m}^{2}$, servindo de fundação para as habitações. As alturas variam entre 1 a $3 \mathrm{~m}$.

Esses três materiais apresentam pequenas diferenças quanto aos parâmetros de resistência e características fisicas, como pode ser visto na Tabela 1. As amostras de colúvio e aterro apresentaram-se um pouco mais argilosas que as amostras de tálus. Os parâmetros de resistência também diferem ligeiramente, sendo as amostras de colúvio e aterro mais coesivas. 
Tabela 1. Parâmetros geotécnicos da matriz dos depósitos que cobrem o Talude Taquaril.

\begin{tabular}{|c|c|c|c|c|c|c|c|c|c|c|c|c|c|c|c|c|}
\hline \multirow{3}{*}{$\begin{array}{l}\frac{\pi}{\omega} \\
\stackrel{0}{0} \\
\stackrel{0}{<}\end{array}$} & \multirow{3}{*}{$\begin{array}{l}\text { Ponto de } \\
\text { coleta da } \\
\text { amostra } \\
\text { no talude }\end{array}$} & \multirow{3}{*}{$\frac{\rho_{\mathrm{s}}}{\mathrm{g} / \mathrm{cm}^{3}}$} & \multirow{3}{*}{$\frac{\rho_{\text {nat }}}{\mathrm{g} / \mathrm{cm}^{3}}$} & \multirow{3}{*}{$\frac{\rho_{d}}{\mathrm{~g} / \mathrm{cm}^{3}}$} & \multirow{3}{*}{$\frac{\mathrm{LL}}{\%}$} & \multirow{3}{*}{\begin{tabular}{|l|} 
LP \\
$\%$
\end{tabular}} & \multirow[t]{2}{*}{ e } & \multirow{2}{*}{$\mathrm{n}$} & \multirow[t]{2}{*}{$\mathrm{C}$} & \multirow[t]{2}{*}{$\phi$} & \multicolumn{6}{|c|}{ Granulometria } \\
\hline & & & & & & & & & & & $\frac{\sigma}{\bar{\sigma}}$ & $\frac{\Phi}{\stackrel{5}{\omega}}$ & 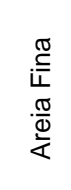 & 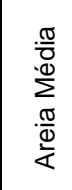 & 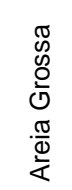 & 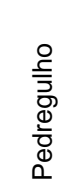 \\
\hline & & & & & & & & & & & $\%$ & $\%$ & $\%$ & $\%$ & $\%$ & $\%$ \\
\hline Taq-1 & Colúvio & 2.79 & 1.38 & 1.21 & 40 & 18 & 1.31 & 57 & 10 & 28 & 25 & 35 & 14 & 6 & 6 & 15 \\
\hline Taq-2 & Colúvio & 2.78 & 1.38 & 1.21 & 40 & 18 & 1.30 & 57 & --- & ---- & 21 & 33 & 10 & 4 & 4 & 28 \\
\hline Taq-3 & Aterro & 2.77 & 1.34 & 1.22 & 41 & 26 & 1.27 & 56 & ---- & ------ & 29 & 35 & 13 & 4 & 5 & 14 \\
\hline Taq-4 & Saprolito & 2.82 & 1.74 & 1.55 & 34 & 14 & 0.81 & 45 & 24 & 16 & 13 & 37 & 18 & 5 & 5 & 22 \\
\hline Taq-5 & Tálus & 2.75 & 1.48 & 1.33 & 33 & NP & 1.07 & 52 & 6 & 33 & 4 & 25 & 13 & 7 & 4 & 47 \\
\hline Taq-6 & Colúvio & 2.76 & 1.38 & 1.33 & 40 & 21 & 1.08 & 52 & --- & ------ & 26 & 44 & 16 & 4 & 2 & 7 \\
\hline Taq-7 & Tálus & 2.78 & 1.48 & 1.33 & 40 & 13 & 1.09 & 52 & --- & ------ & 11 & 36 & 12 & 5 & 8 & 29 \\
\hline Taq-8 & Tálus & 2.77 & 1.48 & 1.25 & 42 & NP & 1.22 & 55 & ---- & ------ & 10 & 60 & 28 & 1 & 1 & 0 \\
\hline Taq-9 & Tálus & 2.80 & 1.48 & 1.25 & 36 & NP & 1.24 & 55 & 6 & 28 & 6 & 45 & 23 & 3 & 4 & 19 \\
\hline
\end{tabular}

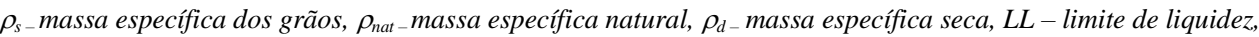

$L P$ - limite de Plasticidade, $N P=$ não plástico, $e$-índice de vazios, $n$-porosidade, $c$ - coesão ( $k P a)$, $\phi$ - ângulo de atrito

\subsection{1 - Análise cinemática}

A área exposta do maciço de filito permitiu a observação de famílias de descontinuidades caracterizadas por dois sistemas juntas e uma foliação penetrativa. A Tabela 2 apresenta um resumo das características avaliadas no maciço.

O diagrama da Figura 6 representa as descontinuidades presentes, as faces do talude e o círculo de atrito utilizado na análise.

Através do diagrama é possível reconhecer a possibilidade de ruptura em cunha pela interseção das descontinuidades $\mathrm{J} 2$ e J3 e de ruptura planar ao longo do plano J2. A foliação encontra-se confinada e com mergulho oposto para sudeste. A linha de interseção da cunha apresenta mesmo sentido de mergulho da face do talude, ou seja mergulhando $35^{\circ}$ para noroeste. Esta linha está na área de instabilidade formada entre o círculo de atrito e o plano do talude, o que favorece a ruptura em cunha. Entretanto, durante o tempo em que o talude foi vistoriado, as rupturas em cunha e planares nunca ocorreram. Apesar da disposição favorável das descontinuidades, outros aspectos devem ser levados em conta durante a análise de estabilidade do talude, como as características de coesão dos planos e grau de saturação.

As Classificações RMR (Bieniawiski, 1989) e Q (Barton, 1974) do maciço foram realizadas para a obtenção de valores aproximados dos parâmetros de resistência. As tabelas 3 e 4 apresentam, respectivamente, os resultados das duas classificações.

Tabela 2. Parâmetros de caracterização das descontinuidades conforme ISRM (1983)

\begin{tabular}{l|l|l|l|l|l|l|l|l}
\hline & $\begin{array}{l}\text { Atitude } \\
\text { (média) }\end{array}$ & $\begin{array}{l}\text { Abertura } \\
\text { (mm) }\end{array}$ & Preenchimento & Rugosidade & Espaçamento & Persistência & Percolação & Resistência \\
\hline Talude & $320 / 50$ & & & & & & $>20$ & Seco* \\
\hline Foliação & $150 / 65$ & 1 a 5 & ausente & Plano/lisa & $<3 \mathrm{~cm}$ & $\begin{array}{l}\text { Rocha muito } \\
\text { fraca }\end{array}$ \\
\hline J2 & $316 / 35$ & 3 a 5 & Silte/ausente & Plano/rugosa & 5 a $17 \mathrm{~cm}$ & $\begin{array}{l}\text { Rocha muito } \\
\text { fraca }\end{array}$ \\
\hline J3 & $40 / 85$ & 3 a 7 & Silte/ausente & Plano/rugosa & 8 a $30 \mathrm{~cm}$ & 3 a $10 \mathrm{~m}$ & Seco* & Secha muito \\
* condição no dia da vistoria.
\end{tabular}


Tabela 3. Classificação RMR do maciço rochoso do Talude Taquaril

\begin{tabular}{l|l|l|l|l|l|l|l|l}
\hline & $\begin{array}{l}\text { Atitude } \\
\text { (média) }\end{array}$ & $\begin{array}{l}\text { Abertura } \\
(\mathbf{m m})\end{array}$ & Preenchimento & Rugosidade & Espaçamento & Persistência & Percolação & Resistência \\
\hline Talude & $320 / 50$ & & & & & & & \\
\hline Foliação & $150 / 65$ & 1 a 5 & ausente & Plano/lisa & $<3 \mathrm{~cm}$ & $>20$ & Seco* & $\begin{array}{l}\text { Rocha muito } \\
\text { fraca }\end{array}$ \\
\hline J2 & $316 / 35$ & 3 a 5 & Silte/ausente & Plano/rugosa & 5 a $17 \mathrm{~cm}$ & 3 a $10 \mathrm{~m}$ & Seco* & $\begin{array}{l}\text { Rocha muito } \\
\text { fraca }\end{array}$ \\
\hline J3 & $40 / 85$ & 3 a 7 & Silte/ausente & Plano/rugosa & 8 a $30 \mathrm{~cm}$ & 3 a $10 \mathrm{~m}$ & Seco* & $\begin{array}{l}\text { Rocha muito } \\
\text { fraca }\end{array}$ \\
\end{tabular}

Tabela 4. Classificação do Sistema Q para o Talude Taquaril

\begin{tabular}{|c|c|}
\hline Índices & Talude do Taquaril \\
\hline Jn & 15 \\
\hline RQD & 47 \\
\hline $\mathrm{Ja}$ & 3 \\
\hline Jw & 0,66 \\
\hline $\mathrm{Jr}$ & 1,5 \\
\hline SRF & 5 \\
\hline RQD/Jn & 3,13 \\
\hline $\mathrm{Jr} / \mathrm{Ja}$ & 0,5 \\
\hline Jw/SRF & 0,132 \\
\hline$\phi$ & $27^{\circ}$ \\
\hline Q & $0,206=$ Muito ruim \\
\hline
\end{tabular}

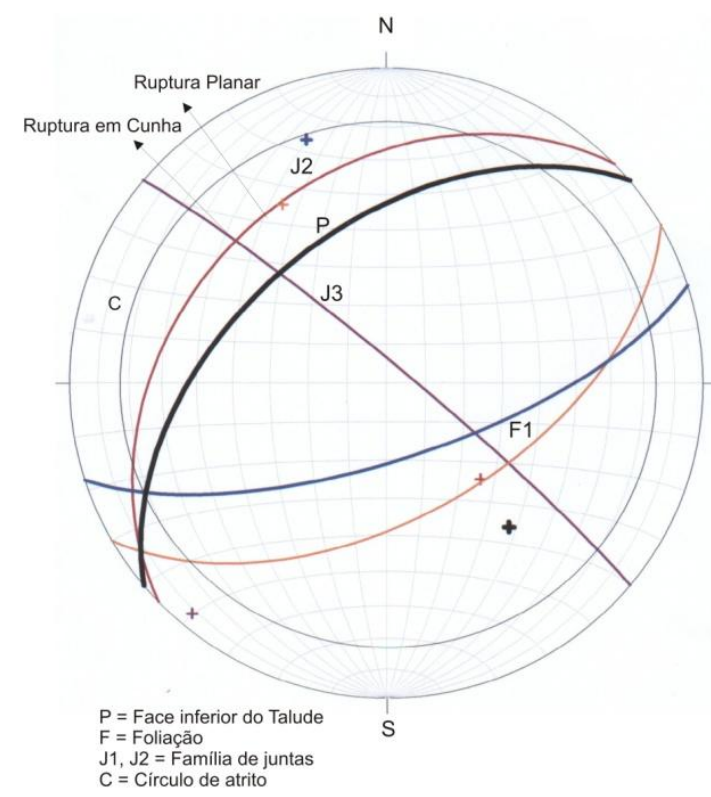

Figura 6. Estereograma de Schimidt exibindo as principais descontinuidades do Talude Taquaril e suas relações com a estabilidade.

A classificação do maciço conforme o critério RMR de Bieniawiski foi classe III (nota $=42$ ), ou seja, maciço regular com valores prováveis de ângulo de atrito entre $21^{\circ}$ e $40^{\circ}$ e coesão entre 100 a $200 \mathrm{kPa}$. Pelo critério de Barton, o ângulo de atrito encontrado foi de $27^{\circ}$, (dentro da faixa de valores de atrito da classificação RMR), porém o maciço foi considerado muito ruim. O Sistema $Q$ não oferece valores de coesão. O valor mínimo de coesão de 100
$\mathrm{kPa}$, fornecido pela Classificação RMR foi utilizado como parâmetro para o cálculo de fator de segurança das rupturas em cunha e planar, assim como o ângulo de atrito de $27^{\circ}$.

\subsection{2- Análise do Equilíbrio Limite para Rupturas} em Cunha e Planar

O fator de segurança para a ruptura em cunha foi calculado a partir do método de Hoeck Bray (1981) que inclui coesão e pressão de água e, para os cálculos, utilizou-se o programa Wedge Failure Analysis. Os dados de entrada incluem as direções do talude e das descontinuidades envolvidas, como também a massa específica da rocha, a massa específica da água, o estado de saturação e os parâmetros de resistência C (coesão) e $\phi$ (ângulo de atrito), todos relacionados na Tabela 5. A análise incluiu duas condições para as descontinuidades: saturadas e secas. No caso da condição saturada o fator de segurança para a ruptura em cunha foi 0 . Para a condição seca o fator de segurança foi de 3,7. Para a ruptura planar foram encontrados os fatores de segurança de 0,9 e 1,9, respectivamente, para as condições saturada e seca.

Diante dos resultados e da não ocorrência das rupturas previstas, pode-se concluir que o maciço rochoso não se tornou saturado em nenhum momento durante os períodos chuvosos vistoriados. Aparentemente, esse fato relaciona-se com as características de permeabilidade e resistência do maciço. Costa (2002), encontrou valores da ordem de 10-4 e 10-5 cm/s para maciços do Grupo Sabará em Belo Horizonte.

A permeabilidade baixa do maciço, associada à presença de coberturas coluviais e aterros ao longo das encostas, pode estar atribuída à condição não saturada do maciço, implicando em maior segurança com relação às rupturas descritas. As descontinuidades mais rugosas e com pequena abertura também são parâmetros que dificultam a percolação da água, conforme Fiori \& Carmignani (2001). Rupturas de pequeno porte, como queda de blocos menores e tombamentos, tornam-se mais comuns. 
Tabela 5. Dados de entrada para cálculo do FS do Talude do Taquaril - Rupturas em cunha e planar

\begin{tabular}{|c|c|c|c|}
\hline \multirow{2}{*}{\multicolumn{2}{|c|}{ Dados de entrada }} & \multicolumn{2}{|l|}{ Análise de Estabilidade } \\
\hline & & Ruptura em Cunha & Ruptura Planar \\
\hline \multicolumn{2}{|c|}{ Ângulo de atrito } & $27^{\circ}$ & $27^{\circ}$ \\
\hline \multicolumn{2}{|c|}{ Coesão } & $100 \mathrm{kPa}$ & $100 \mathrm{kPa}$ \\
\hline \multicolumn{2}{|c|}{ Altura do talude } & $25 m$ & $25 \mathrm{~m}$ \\
\hline \multicolumn{2}{|c|}{ Peso específico da rocha intacta ${ }^{* 1}$} & $21 \mathrm{kn} / \mathrm{m}^{3}$ & $21 \mathrm{kn} / \mathrm{m}^{3}$ \\
\hline \multicolumn{2}{|c|}{ Peso específico da água } & $9,8 \mathrm{kn} / \mathrm{m}^{3}$ & $9,8 \mathrm{kn} / \mathrm{m}^{3}$ \\
\hline \multicolumn{2}{|c|}{ Atitude das descontinuidades $\mathrm{J} 2 \mathrm{e} \mathrm{J} 3$} & $316 / 35$ e $40 / 85$ & $316 / 35$ \\
\hline \multicolumn{2}{|c|}{$\begin{array}{l}\text { Orientação da face do talude } \\
\text { considerada }\end{array}$} & $320 / 50$ & $320 / 50$ \\
\hline \multicolumn{4}{|l|}{ RESULTADOS: } \\
\hline \multirow{2}{*}{$\begin{array}{l}\text { FATORES DE } \\
\text { SEGURANÇA }\end{array}$} & Condição saturada & 0 & 0,9 \\
\hline & Condição seca & 3,7 & 1,9 \\
\hline
\end{tabular}

A permeabilidade baixa do maciço, associada à presença de coberturas coluviais e aterros ao longo das encostas, pode estar atribuída à condição não saturada do maciço, implicando em maior segurança com relação às rupturas descritas. As descontinuidades mais rugosas e com pequena abertura também são parâmetros que dificultam a percolação da água, conforme Fiori \& Carmignani (2001). Rupturas de pequeno porte, como queda de blocos menores e tombamentos, tornam-se mais comuns.

\subsection{3 - Retroanálise das Rupturas Circulares das} coberturas coluviais e tálus

Durante a vistoria do talude, por dois períodos chuvosos consecutivos, foi possível observar que a ruptura mais freqüente que ocorre tanto no talude quanto em outras encostas do Taquaril, é a ruptura circular pouco profunda dos depósitos de tálus, colúvios e aterros que cobrem os maciços de filitos. O talude Taquaril já apresentava cicatrizes de ruptura circular (vide Fig 4). Durante o mês de Janeiro de 2003 ele se rompeu formando duas grandes cicatrizes de ruptura: a primeira, localizada na face superior do talude, ocorreu no depósito de tálus e a segunda, localizada na face inferior do talude, ocorreu no colúvio, como pôde ser visto na Figura 5.

Através do perfil topográfico do Talude Taquaril , mostrado na Figura 7, observa-se:

- a topografia do talude anterior à ruptura de janeiro/2003

- as duas superfícies de ruptura ocorridas em janeiro/2003

- a posição do depósito de tálus e de colúvio, respectivamente, na face superior do talude e na face inferior do talude

- o maciço rochoso subjacente às coberturas com suas descontinuidades principais

Para a execução da retroanálise da ruptura de janeiro de 2003 utilizou-se: as informações topográficas do talude, a posição conhecida das superfícies de ruptura e dos parâmetros geotécnicos (Tabela 4) obtidos durante os ensaios laboratoriais.

Os solos analisados foram considerados como não saturados, no momento da ruptura, segundo os preceitos de Fontoura et al. (1984).

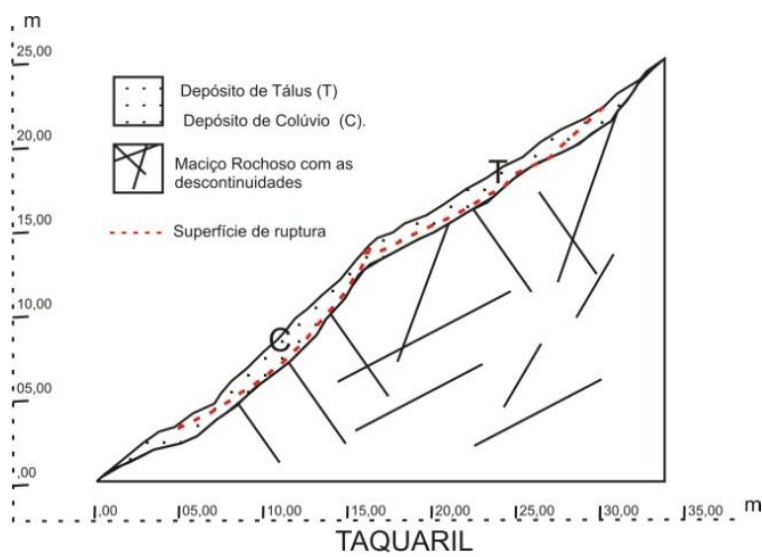

Figura 7- Perfil do Talude Taquaril exibindo as condições da ruptura de janeiro de 2003

Para a simulação dos parâmetros de poro pressão utilizou-se o coeficiente $r_{u}$ :

$$
r_{u}=u / \gamma h(1)
$$

ou seja:

$\mathrm{u}=$ poro pressão da água; $\mathrm{y}=$ massa específica do solo e $\mathrm{h}=$ profundidade de um ponto do maciço de solo abaixo da superfície.

De acordo com Bishop \& Morgenstern (1960), em soluções gerais de estabilidade de talude considerase o coeficiente $r_{u}$ constante ao longo da seção, o que é chamado de distribuição homogênea da poro pressão. Para os autores, valores de $r_{u}$ na faixa de 0 até 0,7 são os mais comumente encontrados. Conforme Fredlung \& Rahardjo (1993), para solos não saturados, valores de $r_{u}$ acima de 0,5 convergem para as condições de artesianismo, desde que a densidade da água seja, aproximadamente, metade da densidade do solo. Dessa forma, durante a retroanálise foram simulados valores de $r_{u}$ variando de 0 até 0 máximo de 0,48 , considerando a espessura (h) de 1,5m dos depósitos. Com 
relação aos parâmetros de resistência, os resultados dos ensaios de cisalhamento direto forneceram os seguintes valores:

Para a coesão: entre 0 a 10, com a coesão maiselevada nos solos coluviais e aterros.

Para o atrito: entre $28^{\circ}$ a $33^{\circ}$.

Todos esses parâmetros foram utilizados até se encontrar o fator de segurança unitário para as
Os resultados obtidos pela retroanálise estão na Tabela 6.

Conclui-se que rupturas circulares de maior extensão e relativamente próximas ao contato solo/maciço ocorrem sob as condições descritas na Tabela 5. Rupturas circulares de menor porte, menos profundas ocorrem sob poro pressões menores $\quad\left(r_{u}<0,47\right)$.

superfícies de ruptura conhecidas.

Tabela 6 - Parâmetros obtidos a partir da retroanálise das rupturas circulares do talude Taquaril, considerando FS = 1 .

\begin{tabular}{llllllll}
\hline \multicolumn{7}{c}{ Ruptura na face superior do talude } \\
\hline material & coesão & atrito & $\mathrm{r}_{\mathrm{u}}$ & $\gamma$ & $\mathrm{h}(\mathrm{m})$ & Poro pressão & $\mathrm{FS}$ \\
\hline tálus & 4 & 33 & 0,47 & 15 & 1,5 & $11 \mathrm{kPa}$ & 1 \\
\hline colúvio & 7 & & Ruptura na face inferior do talude & & \\
\hline
\end{tabular}

Através dos ensaios de permeabilidade in situ, obteve-se a condutividade hidráulica tanto para o tálus quanto para o colúvio como sendo da ordem de $10^{-4}$, valor relativamente baixo. Este valor é coerente para solos siltosos, silto arenosos e silto argilosos, conforme Terzaghi \& Peck (1962). Como o índice de vazios dos dois materiais foi alto (amostras de colúvio e tálus, Tabela 4), atribuí-se à composição do material, mais rico em elementos micáceos e areia fina, a baixa condutividade hidráulica obtida. Conforme já mencionado, a permeabilidade dos saprolitos do Grupo Sabará tem sido da ordem de $10^{-4}$ a $10^{-5} \mathrm{~cm} / \mathrm{s}$. Isso torna o maciço rochoso pouco mais impermeável que sua cobertura, o que pode refletir no aumento de poro pressões ao longo da superfície de contato.

Em janeiro de 2003, especialmente no dia 15 , data do escorregamento, houve uma taxa de precipitação excepcional com valor de $217 \mathrm{~mm}$, a qual somada aos $65 \mathrm{~mm}$ dos 3 dias anteriores completaram um total de $282 \mathrm{~mm}$ acumulados em 4 dias. Mediante essa elevada taxa de precipitação, facilmente poro pressões acima $10 \mathrm{kPa}$ foram alcançadas. A baixa permeabilidade e alto índice de vazios da cobertura em contato com maciço, também pouco permeável, favorecem rupturas em condições não drenadas e não saturadas.

\section{CONCLUSÕES}

O maciço rochoso constituído por filitos, xistos e metagrauvacas do Grupo Sabará está em avançado estado de alteração e com descontinuidades, muitas vezes, em posições favoráveis a rupturas em cunha, planar e tombamentos de pequeno porte, como observado na área do Taquaril durante períodos chuvosos. O grau de saturação do maciço é fator importante no desencadeamento dessas rupturas e, neste caso, a baixa permeabilidade do maciço, a pequena abertura das descontinuidades e a presença das coberturas de aterro, coluviais e tálus, retardam a infiltração de água nos maciços, favorecendo a estabilidade.

Os maciços, especialmente filitos, quando sem cobertura sobrejacente e em contato direto com a água, chegam a elevados estados de alteração, tornando-se, inclusive pulverulentos. Nestas circunstâncias, a baixa resistência do maciço pode gerar rupturas ao longo das descontinuidades com maior facilidade.

A baixa permeabilidade dos depósitos favorece ruptura em condições não saturadas. As rupturas mais expressivas são do tipo circular e ocorrem próximas à superfície de contato do solo com 0 maciço rochoso. Durante períodos de chuvas menos intensas, as rupturas circulares são de menor porte e, necessariamente, não se aproximam da superfície de contato solo/rocha.

Os parâmetros de resistência obtidos na retroanálise e nos ensaios de cisalhamento para os depósitos coluviais são de $7 \mathrm{kPa}$ para a coesão e $28^{\circ}$ para o atrito. Estes parâmetros podem ser atribuídos aos aterros pelas suas semelhanças com os colúvios. Para os depósitos de tálus os parâmetros de resistência são de $4 \mathrm{kPa}$ para a coesão e $33^{\circ}$ para o atrito. Poro pressões baixas, da ordem de $10 \mathrm{kPa}$ foram suficientes para aproximar o talude da condição de equilíbrio limite.

Os dados obtidos pela retroanálise podem contribuir para projetos de monitoramento ou 
reabilitação dos taludes. É importante enfatizar a necessidade de instalação de drenos para que as poro pressões não atinjam os valores encontrados. A população deve evitar muros de contenção de concreto que impermeabilizem os cortes. As lonas plásticas, que evitam a infiltração, podem ajudar temporariamente, mas acabam permitindo a infiltração da água.

\section{6 - REFERÊNCIAS BIBLIOGRÁFICAS}

Augusto Filho O. 1995. Escorregamento em encostas naturais e ocupadas: Análise e controle. In: Bitar O.Y. (ed.) Curso de Geologia Ambiental. São Paulo, ABGE/IPT, 77-100.

Augusto Filho O. \& Virgill J.C. 1998. Estabilidades de Taludes. In: Oliveira A.,M,S. \& Brito S.N.A. (ed.) Geologia de Engenharia. São Paulo, ABGE, p.243-269.

Balaam N.P. 2001. Slope Stability Analysis - User's Manual for Program XSlope for windows. Centre for Geotecnhical research - University of Sydney, 98p.

Barton N., Lien R., Lunde J. 1974. Engineering Classification of Rock Masses. Rock Mechanics. 6(4): 189 - 236.

Bieniawski Z.T. 1989. Engineering rock mass classification. New York: John Wiley. 215p.

Bishop A.W. 1955. The Use of the Slip Circle in the Stability Analysis of Earth Slopes, Geotechnique, 5: 7-17.

Bishop A.W \& Morgenstern N. 1960. Stability Coefficients for earth slopes. Geotechnique, 10(4): 129-147.

Costa W.D. 2002. Caracterização das Condições de Uso e Preservação das Águas Subterrâneas do Município de Belo Horizonte - MG, Universidade de São Paulo - USP, São Paulo, Tese de doutorado. $350 \mathrm{p}$.

Duncan J.M. 1996. Soil Slope Stability Analysis. In: Turner A. K \& Schuster R.L. (ed.) Landslides - Investigation and Mitigation, Special Report. Washington D.C., National Academy Press, 247: 337 - 371.
Fontoura S.A.B, Campos L.E.P., Filho L.M.C. 1984. A Reanalysis of some Slides in Gneissic Residual Soils. In: International Symposium on Landslides, IV, Toronto, Proceedings, 1: 625629.

Fiori A.P. \& Carmignani L. 2001. Fundamentos de mecânica dos solos e das rochas, aplicações na estabilidade de taludes. Ed. UFPR. 548p.

Fredlund D.G \& Rahardjo H. 1993. Soil Mechanics for unsaturated soils. New York, John Wiley \& Sons, inc.517p.

Hoeck E. \& Bray J. 1981. Rock Slope Engineering. London, IMM \& Elsevier Applied Science. 527p

ISRM - International Society for Rock Mecanics. 1983. Métodos Para a Descrição Quantitativa de Descontinuidades em Maciços Rochosos. São Paulo, ABGE e Comitê Bras. De Mec. Das Rochas. 132p. (Tradução no12.).

Kroeger E.B. 1999. Slope Stability Software, 1: 1-3. Disponível em http://www.engr.siu.edu/mining/kroeger.

Kroeger E.B. 2000. Analysis of plane failures in compund slopes. International Journal of Surface Mining, Reclamation and Environment, 14: 215-222.

Parizzi M.G, Porto C.G, Piumbini B.S. 2002. Caracterização geológica-geotécnica e avaliação do risco do Conjunto Taquaril, Belo Horizonte (MG). In: Congresso Brasileiro de Geologia de Engenharia e Ambiental, Ouro Preto, ABGE, Anais CdRom. 10: 15p.

Piumbini B.S., Porto C. G.1999. Caracterização Geológicogeotécnica e avaliação do risco do Conjunto Taquaril, Belo Horizonte (MG). Instituto de Geociências, Universidade Federal de Minas Gerais, Belo Horizonte, Trabalho Geológico de Graduação, 155p.

Silva A.S., Carvalho E.T, Fantinel L.M., Romano A.W., Viana C.S. 1995. Estudos Geológicos, Hidrogeológicos, geotécnicos e Geoambientais integrados no Município de Belo Horizonte. Convênio: PMBH, SMP, FUNDEP/ UFMG. 490p. (Relatório Final).

Terzaghi K., Peck R.B. 1962. Soil mechanics in engineering practice. New York, John Wiley 659p. 